\title{
Tekno-Bilim ve Üniversitelerin Dönüşümü
}

\author{
Mehmet Firat \\ Anadolu Üniversitesi, Açıköğretim Fakültesi, Uzaktan Öğretim Bölümü, Yunusemre Kampsü, 26470, Eskişehir \\ ORCID: M.Firat (0000-0001-8707-5918)
}

\begin{abstract}
Özet
Modern toplumda akademik disiplinlerin yapay örgütlenmesi ile oluşan üniversiteler dijital dünyanın yeni normallerinde ağır bir ontolojik sancı çekmektedir. Dünyanın bir tasarıma dönüștüğü modern endüstri çağında düşünürün kaybolduğu, yerine araştırma projelerine gömülmüş araştırmacı tipinin oluştuğuna şahit olduk. Hiper hızda işleyen dijital dünyada ise hem düşünen hem de üreten, çok yönlü akademisyen profili şekillenmeye başladı. Bu profili mümkün kılan șeyler ise yükselen açık bilim paradigması ve dijital dönüșüm olarak görünmektedir. Bu çalışmada Immanuel Kant, Martin Heidegger, Theodor W. Adorno, Max Horkheimer ve Jacques Derridánın görüşleri temelinde üniversitelerde yaşanan dönüşüm ele alınmış ve dijital çağda üniversitelerin hem ontolojik olarak hem de fonksiyonel olarak etkilendiği gelişmeler tartışılmıştır.
\end{abstract}

Anahtar Kelimeler: Üniversiteler, dijital dönüşüm, tekno-bilim, açı bilim

\section{Techno-Science and Transformation of Universities}

\begin{abstract}
Universities formed by the artificial organization of academic disciplines in modern society suffer a heavy ontological pain in the new norms of the digital world. In the modern industrial era, when the world turned into a design, we witnessed the disappearance of the thinker, and the type of researcher that was embedded in research projects. In the digital world that operates at a hyper-speed, a new academician profile was started to take shape. What makes this profile possible is the emerging of open science paradigm and digital transformation. In this study, the transformation in universities was discussed based on the opinions of Immanuel Kant, Martin Heidegger, Theodor W. Adorno, Max Horkheimer and Jacques Derrida.
\end{abstract}

Keywords: Universities, digital transformation, techno-science, open science

\section{GiRiş}

İlk kez modern toplumlarda şekillenen günümüz üniversiteleri 21. yüzyılda yapı ve işleyiş açısından göz ardı edilemez bir dönüşüm içerisindedirler. Bu dönüşümü daha iyi anlamak için medya devriminin derin etkilerinin yanında üniversitelerin ontolojik yapılarındaki değişimi de görmekte fayda vardır. Bu noktada derin analizleri olan Immanuel Kant, Martin Heidegger, Theodor W. Adorno, Max Horkheimer ve Jacques Derrida'nın görüşleri oldukça dikkat çekicidir. $\mathrm{Bu}$ analizlere geçmeden önce üniversitelerin ontolojik yapısındaki değişimi tetikleyen bilimsel dönüşümlere bakmakta yarar vardır.

\section{BíLimin DÖNÜşÜMÜ}

Bilim tarihinde dönüşüm paradigma değişimleri ile mey-

*Yazışma Adresi / Address for Correspondence:

M. Firat, Email:mfirat@anadolu.edu.tr

Geliş Tarihi / Received Date: 09.07.2020

Kabul Tarihi / Accepted Date: 10.08.2020

Doi: $10.26701 /$ uad.767276 dana gelir. Kuhn (2008) bilimde paradigmayı; dönemin yaygın siyasi, ekonomik ve toplumsal eğilimlerinden etkilenen ortak değerler ve anlayışlar dizisi olarak ele alır. Farklı dönemlerde bilime bakış da büyük ölçüde günün paradigmasına bağlı olarak birbirinden farklıdır. Bilim tarihinde sıklıkla modern bilim sonrası pozitivist ve post-pozitivist paradigmalardan bahsedilir. Ancak Firat, (2020) tarihteki 6 farklı bilim paradigmasından bahseder. Her biri kendi dönemini temsil eden bu paradigmalar tarihsel sıralama içerisinde aşağıda verilmiştir.

1. Heuristic (Sezgisel) Bilim: Antik Sümer, Babil, Mısır ve Hindistan'daki bilimi temsil eder.

2. Doğa Felsefesi: Helenistik çağdaki (Thales, Pisagor, Aristo, Plato...) bilimi temsil eder.

3. Pragmatik Bilim: İslam dünyasındaki (Hazrezmi, İbn-i Sina, Farabi, Biruni...) bilimi temsil eder.

4. Kâşifler Çağı: Ortaçağ Avrupa'sındaki (Marco Polo, Cristopher Colombus, Ferdinand Macellan...) bilimi temsil eder.

5. Pozitivist Bilim: Deney ve gözleme dayalı (Auguste Comte) bilimi temsil eder.

6. Post Pozitivist Bilim: Pozitivizm sonrası bilimi (A.Einstein, T.Kuhn, M.Weber) temsil eder. 


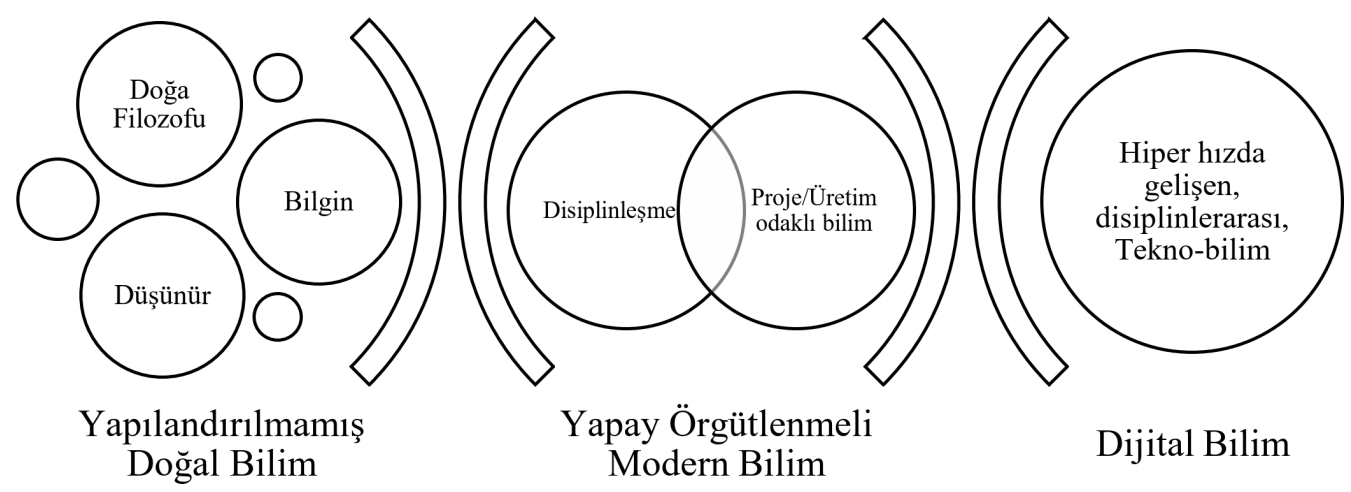

Şekil 1. Bilim dönüşümünün 3 adımı

Pozitivist bilim paradigmasından sonra şimdilik post-pozitivist paradigma olarak adlandırılan dönem yaşanmaktadır. Bu bilim döneminde hem dijital teknolojilerin hem de açık bilim anlayışının yaygınlaşmaya başladığı düşünülmektedir. Benzer şekilde her dönemin kendine özgü öncülleri olduğu gibi bazı dönemlerin ortak bazı özellikleri de bulunmaktadır. İncelenecek olan bu ortak özelliklerdeki değiş̧imi de bilimsel dönüşüm olarak değerlendirmek mümkündür. $\mathrm{Bu}$ temelde, yukarıda sıralanan bilimsel dönemleri geçirdikleri dönüşümler açısından 3 kategoride özetlemek de mümkündür. Bu üç temel bilimsel dönüşüm Şekil 1'de verilmiştir.

Modern bilim anlayışından önce gerçekleştirilen bilimsel çalışmalar yapılandırılmamış bilim olarak adlandırılabilir. Çünkü bu dönemlerde genel kabul gören bir disiplinleşme, standartlaşma ve yapılandırılmış alanlar yoktu. Ardindan gelen modern bilimde ise bunun tam tersi olarak yapılandırılmış bir bilim anlayışı söz konusudur. Bu anlayışta her disiplin kendi alanına odaklanmalıdır. Ancak bu șekilde derin araștırma ve ilerleme sağlanabilir. $\mathrm{Bu}$ dönemde bilimin yapay örgütlenmesi bilimsel alanlarda derinliği desteklemiş olsa da gerçek dünyanın bir bütün olarak ilişkili olması nedeniyle eleştirilmiștir. Bu temelde, modern bilim eleştirisi yükselerek post-pozitivist bilime evirilmiştir. Ancak post-pozitivist bilim bir eleştiri olmanın ötesine geçip, kabul gören bir bilim tasarımını henüz ortaya koyamamıştır.

Bilimdeki asıl dönüşüm pozitivist ve post-pozitivist bilim paradigmalarının savaşı devam ederken bilimin teknoloji eğiliminde meydana gelmiştir. Bilimde teknoloji eğilimi güncel bilişim teknolojilerindeki dikkat çekici yükseliş ile başlamış ve hemen her alanı derinden etkilemiştir.Tekno-bilim olarak adlandırılan bu dönüşüm popüler bilimin teknoloji ve mühendislik alanlarına yönelmesi ile ortaya çıkmıştır (Bowler, 2009, s. 25). Heidegger, Adorno, Horkheimer ve Derrida gibi önemli düşünürler bu eğilimi bilimin eleştirel düşünme ve akıl yürütme geleneğine karşı bir tehlike olarak değerlendirmişlerdir.

\section{TEKNO-BILLIM}

Martin Heidegger (1996), "akademik disiplinlerin yapay örgütlenmesi” ile ilgili olarak, yalnızca üniversite ve fakül- telerin teknik örgütlenişleri ile bir arada tutulabildiğini ve ancak pratik amaçlar doğrultusunda anlamlı bir birim olarak sürdürülebildiklerini savunmaktadır. Bununla birlikte Heidegger, insanı ilgilendiren bütün alanlara yönelik her türlü araştırma, düşünme ve anlama çabasının temelini oluşturan "sıkı çalışma (Die strenge)" ile matematikleștirme idealini tek doğru yolmuşçasına izleyen akademik disiplinlerin aradığı "kesinlik (Die Exaktheit)" arasında bir ayrım yapmıştır (Nalbantoğlu, 2009).

Birinci tür uğraşa Almanya'da “Tinbilimciler”, Fransa'da "sciences humaines" ve Kuzey Amerika'da "social sciences" disiplinleri örnek verilebilir. Bütün bu disiplinlerin bir temel dayanak noktası vardır. Heidegger'e göre her tür uygulamalı araştırmanın temelini oluşturan algı "ground plan" dir (Heidegger, 1993; Heidegger, 1996; Ergül, 2003; Nalbantoğlu, 2009; Heidegger, 2015). Ground plan, modern bilimin yöntemi olarak şeyleri öznenin nesnesi haline getiren "istenç istenci" olarak tanımlanmaktadır. Heidegger'in en büyük eleștirisi ikinci tür uğraşa yöneliktir. Heidegger şimdiye kadar açık gerçeklere ulaşacağı zannedilen matematiksel fizik modelini benimsemiş bilim dallarının "ground plan" a kendilerini uydurmakta güçlük çektiklerini vurgulamaktadır. Heidegger 'şeylerin' özneler için nesnelere indirgendiği, dünyanın tasarıma dönüștüğü modern çağda düşünürün kaybolduğu, yerine araştırma projelerine gömülmüş araştırmacı tipinin oluştuğunu ifade etmektedir. Heidegger'in bu ayrımla oluşturduğu disiplin anlayışını Şekil 2'deki gibi özetlemek mümkündür.

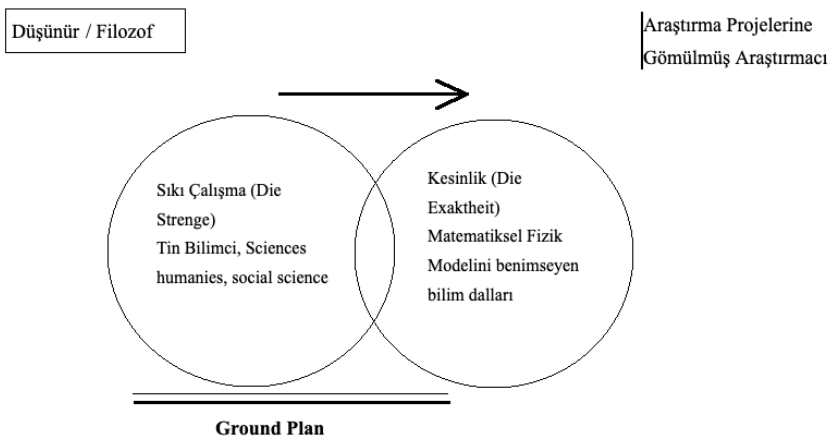

Şekil 2. Heidegger'in Akademik Uğraşlar Ayrımı

Heidegger'in akademik uğraşlar ayrımında "kesinliğe" dayanan pozitif bilimlerine yaptığı bu eleștiri temelde 
amaçsızlaşan bir pozitif bilim anlayışının günün koşullarında başat rol üstlenen teknoloji ve ekonomi faktörlerinden hizla etkilenmesine yöneliktir. Günümüz pozitif bilim alanlarında yapılan araştırmaların akademik değerlerinden ziyade kullandıkları teknolojilerin ve bütçelerinin ön plana çıkması Heidegger'in bu kaygısını doğrular niteliktedir. Adorno ve Horkheimer (2007) ise endüstriyel tekniklerin hükmettiği günümüz toplumuna ve sosyal bilimlerin ampirikleşmesine dikkat çekmiştir. Tekno-bilim ve pazarın "uygulamalı" disiplinlere verdiği aşırı pirim, temel bilimsel araştırmalar yapmaya dönük doğa, insan ve toplum bilimlerini, hatta felsefeyi pragmatik kaygılarla daha da olumsuz etkilemektedir (Nalbantoğlu, 2009).

Frankfurt Okulunun başlıca temsilcileri 1950'lerin başında endüstrileşmiş kapitalist ülkelerin toplumsal-kültürel eğilimlerini betimlemede "Kültür Endüstrisi" kavramını kullanmışlardır. Pazara ve teknolojikleşen dünyaya ayak uydurmakta zorlanan üniversitelerin de bu süreçlerde ciddi yapısal sorunlar yaşadığı söylenebilir. Kültür endüstrisi ve tekno-bilim koşullarına uymaya zorlanan üniversitelerde oluşturulan her yeni bölüm, her 'disiplinlerarası' eğitim programı ya da merkez 'hızlı getiri’ sağlaması beklenen bir 'yatırım' olarak düşünülmeye başlanmıştır (Nalbantoğlu, 2009).

Immanuel Kant (1992) salt ampiriğe yönelen teknik üniversitenin karşısına 'arı akla' dayanan üniversiteyi koyarken Hegel (2004) okulu var olan sistemin basit bir yansıması olarak görmüştür. Günümüz felsefecilerinden Jacques Derrida ise akla karşıt olarak kurulmuş tek bir üniversitenin olmadığını ama üniversitenin, özellikle modern çağda üniversitesinin, üzerine kurulduğu akıl temelini sorgusuz kabullenmek yerine bu temele biraz daha kuşkucu yaklaşmamız gerektiğini savunmuştur.

Üniversitelerin günümüzde "kitle üniversitesi" olma yönünde geçirdiği değişikliklerle bilgi fabrikalarına dönüşme eğilimleri beraberinde değișen öğretim üyesi profili için yeni beklentiler de oluşturmaktadır. Nalbantoğlu, (2009) teknolaşan bilim alanlarının seri imalata dönüşmesinin getirdiği kalıplara dayalı tekdüzelik ve kısırlaşmanın içsel gelenek ve bellek üzerinde ölümcül etkisi olduğunu vurgulamıştır.

Üretim odaklı bir anlayışın üniversitelerde felsefe yapan düşünür profilindeki akademisyeni değişime zorladığını söylemek mümkündür. Üretim ile kast edilen şey sadece patent, proje ve makale olursa elbette kısır bir sürece girilebilir. Ancak yeni dönemde üretim; patent, proje ve makalelerin yanında eğitim ve öğretim faaliyetlerindeki performansı da dahil eden, günün bilgi ve iletişim teknolojilerinden yararlanılarak yapılan etkinlikleri (seminerler, webinarlar, çevrimiçi dersler), katkıları (hakemlikler, editörlükler, sözlük tanımları, tartışmalar, jüriler, araştırma dönüt ve düzeltmeleri) ve etkileri (yayın indeksleri, okunma sayıları, takip sayıları, araştırmacı profil puan- ları vb.) de kapsarsa akademisyen profili için öngörülen olumsuzlukların önlenebileceği düşünülmektedir. Çünkü akademisyen sadece üniversitede akademisyen değildir, her zaman akademisyendir. Çalışması için mesai saatlerini beklemez. Benzer şekilde üniversitelerin bilişim teknolojilerinden aktif bir biçimde yararlanarak daha girişimci ve yenilikçi olmaları Yamamoto'nun (2020) da altını çizdiği gibi üniversitelerin dijital çağda nitelik ve kapasitesini arttırabilir.

\section{AKADEMISYEN}

İnternet gibi yeni teknolojilerin yaşamımıza girmesiyle birlikte öğrenenler kadar öğreticilerin de rollerinin değişmesi kaçınılmazdır. Artık geleneksel yöntemlerden çok daha farklı tasarımlara doğru bir yönelim başlamıştır. Bilişim teknolojilerindeki köklü değişimlerin eğitime yansıması göz önüne alındığında yükseköğretim kurumları, dolayısıyla da öğretim üyelerinin, bu yansımaya uygun davranış biçimleri geliştirmek durumunda kalacakları açıktır. Özellikle Covid-19 pandemisi sürecinde bu ihtiyacın ne kadar önemli ve öncelikli olduğu ortaya çıkmıştır. Üniversiteler uzaktan eğitim sistemlerini geliştirmeye çalışırken öğretim üyeleri de uzaktan eğitim teknolojilerini kullanma becerilerini geliştirmek durumunda kalmışlardır. Ancak, açık ve uzaktan öğrenme bilim alanına yönelik yeterli düzeyde hizmet-içi eğitim alınmadığından dolayı uzaktan eğitim kurgusundan uzak hızlandırılmış bir geçişe gidilmiştir. Bu da yüz yüze derslerin çevrimiçi ortama taşınmasıyla sonuçlanmıştır.

Öğretim üyelerinin üstlendikleri görevler açısından, yerine getirmekle sorumlu oldukları iki ana görev alanları vardır. Öğretim ve araştırma. Bilişim toplumu olmada öğretim üyeleri hem öğretimde hem de araştırmada bilişim teknolojilerini bilmek ve de kullanmak durumundadırlar. Günümüz koşulları her bir öğretim üyesinin güncel teknolojik ortamlardan kendi alanlarının yapısına ve işlevlerine uygun olarak yararlanabiliyor olmalarını gerektirmektedir. 19. yüzyılda ve hatta 20. yüzyılın uzunca bir döneminde geçerli olan ve o dönemlerin hiyerarşik toplum yapısına da çok uygun düşen öğretmen merkezli "profesör üniversiteleri” yeni dünya düzeninin gereksinimlerini karşılamaktan uzaktır. Yeni dönemde bireyin, üniversite bağlamında öğrencinin, bilgiye ulaşma kanalları çeşitlenmiştir ve birey kendi fiziksel ve sosyal çevresini düzenleyerek entelektüel yapısını geliştirme şansına sahiptir. Bu bağlamda öğretim üyesinin rolü merkezden uzaklaşarak; bilgilendirmeden yönlendirmeye doğru bir geçiş izlemektedir.

\section{SONUÇ}

Bilimde meydana gelen tarihsel dönüşümler farklı dönemlerde farklı bilim paradigmalarının hüküm sürmesini sağlamıştır. Modern bilim paradigmasında doğan günümüz üniversiteleri yaşanan hızlı gelişmeler (post-pozitivist bilim, dijital bilim ve açık bilim) karşısında ayakta kalmaya çalışmaktadırlar. Heidegger'in (1996) akademik 
uğraşlar ayrımı ve Horkheimer'ın (2007) üretim bandına dönüșen üniversite kaygısı tekno-bilimin metalaşan yapısına dikkat çeker. En büyük tehlike ise bilimin doğal sorgulama ve düşünme odağından ayrılmasıdır. Kant (1992) ve Derrida ise teknik üniversiteye karşı "arı akla" dayalı üniversitenin desteklenmesi gerektiğini vurgular. Nalbantoğlu (2009) bu görüşlere dayanarak teknolaşan bilim alanlarının seri imalata dönüşmesinin tekdüzelik ve kısırlaşmaya yol açacağı konusunda uyarılarda bulunur.

Yapılan tartışmalar bilimsel dönüşümler ışığında değerlendirildiğinde, paradigmanın doğası gereği bilim yapan kurumların da paradigmadan etkilenmeleri beklenir. Dolayısıyla modern bilimde ortaya çıkan üniversitelerin, bilim paradigması değişirken aynı kalmaları, yapısal bir değişim göstermemeleri düşünülemez. En temelde, modern toplumlarda merkezi olan bilgi dijital teknolojilerle dağıtık, esnek ve erişilebilir hale gelmiştir. Eğer ontolojik olarak üniversitenin var olma sebebi proaktif bilgi paylaşımı ise artık binalarının duvarlarının dışına çıkmasının zamanı gelmiştir. Bu dönüşüm seri üretim odaklı tekno-bilime doğru değil açık bilim odaklı kolektif dijital bilime doğru olmalıdır. Bu tıpkı açık ve kapalı kaynak yazllımların mücadelesine benzemektedir. Tekno-bilim üretim ve kâr odaklı kapalı kaynak yazılımları açık bilim ise açık kaynak yazılımları temsil ediyor.

Dijital dünyada üniversiteler, doğru ve güvenilir bilginin merkezi olmaya devam etse de yapı ve işleyişlerinde dönüșüm gerçekleștirmeleri kaçınılmaz görünmektedir. $\mathrm{Bu}$ dönüşüm doğal süreçleriyle zaten başlamıș durumdadır. Sadece bilimsel araştırma açısından değil eğitim-öğretim faaliyetleri açısından da bu böyledir. 2020'de yaşadığımız Covid-19 pandemisinin üniversitelerin öğretim faaliyetlerini büyük ölçüde dijitale taşımasına sebep olması bu dönüşümü daha da hızlandırabilir. Bu noktada modern üniversite geleneğinden yeni dijital dünyaya geçişte dikkat çekici bir yükseliş açık ve uzaktan öğrenme alanında yaşanmaktadır. Üniversiteler için açık ve uzaktan öğrenme artık bir özel durum uygulaması olmaktan çıkmış her öğretim üyesinin ilgilenmesi ve asgari düzeyde bilmesi gereken bir alan haline gelmiştir. Tam da bu nedenle tüm üniversitelerde "açık ve uzaktan öğrenme" kapsamında hizmet-içi eğitimlerin verilmesi üniversitelerin tüm paydaşları için önemli yararlar sağlayacaktır.

\section{KAYNAKÇA}

Adorno, T., \& Horkheimer, M. (2007). The culture industry: Enlightenment as mass deception. Stardom and celebrity: A reader, 34-43.

Bowler, Peter J. (2009). Science for All: The Popularization of Science in Early Twentieth-Century Britain. Chicago: The University of Chicago Press.

Ergül, Ö. H. (2003). Heidegger'in Varoluşçu Ontolojisi. Kaygı Dergisi, (2), 68-72.

Fırat, M. (2020). Açık Bilim: Zamanı Gelmiş Paradigma. Ankara: Nobel Akademik Yayıncilık.
Heidegger, M. (2015). Essays in metaphysics: identity and difference. Open Road Media.

Heidegger, M. (1996). Being and time: A translation of Sein und Zeit. SUNY Press.

Heidegger, M. (1993). What is metaphysics?. Basic writings, 89-110.

Hegel, G. W. F. (2004). Mantık Bilimi, çev. Aziz Yardımlı. İdea Yay., İstanbul.

Kant, I. (1992). The Conflict of the Faculties= Der Streit der Fakultaten. University of Nebraska Press, 901 N. 17th St., Lincoln, NE 68588-0520.

Kuhn, S. T. (2008). Bilimsel Devrimlerin Yapısı (5. baskı). İstanbul: Kırmızı Yayınları.

Nalbantoğlu, H.Ü. (2009). Arayışlar: Bilim, Kültür ve Üniversite, İletişim Yayınları, İstanbul.

Yamamoto, S. G. T. (2020). Girişimci Yenilikçi Üniversite. Üniversite Araştırmaları Dergisi, 3(1), 44-48. 